\title{
Application of response surface methodology on investigating flank wear in machining hardened steel using PVD TiN coated mixed ceramic insert
}

\author{
Ashok Kumar Sahoo , Kashfull Orra and Bharat Chandra Routra
}

\begin{tabular}{l} 
School of Mechanical Engineering, KI T \\
\hline C H R O N I C L E \\
\hline Article history: \\
Received February 82013 \\
Received in revised format \\
July 72013 \\
Accepted July 82013 \\
Available online \\
July 82013 \\
\hline Keywords: \\
Flank wear \\
Hard turning \\
ANOVA \\
Response surface methodology
\end{tabular}

\section{Introduction}

Hard turning is found to be an effective technology and has an advantage over traditional grinding process in recent years. For successful implementation of hard turning, tool wear study is essentially required for achieving higher machinability and economic feasibility. Hard turning is defined as turning steel of hardness $45 \mathrm{HRC}$ and above. Automobile makers have started to use hard turning for semifinished and finished transmission shafts, axles, and engine components, while aircraft manufacturers have applied the technology to the production of flap gears, landing struts and aerospace engine components (Tönshoff et al., 1995). Traditionally, grinding has been a preferred method for machining materials with hardness greater than $50 \mathrm{RC}$. Grinding consumes at least five times more energy per metal removal than cutting. Therefore cutting is more energy efficient than grinding. In recent years,

\footnotetext{
* Corresponding author.

E-mail: aklala72@gmail.com (A. K. Sahoo)

(C) 2013 Growing Science Ltd. All rights reserved.

doi: $10.5267 / \mathrm{j} . \mathrm{ijiec} .2013 .07 .001$
} 
hard machining of steel parts hardened to about $60 \mathrm{HRC}$ performed by both mixed ceramic and CBN tools became very popular and effective technology replacing successively grinding operations. Substantial reduction of manufacturing cycles, manufacturing costs, decrease of set up time, achievement of comparable surface finish, elimination of environmentally harmful coolant observed in hard turning has made this a preferred choice over grinding in many applications.

Sahin and Motorcu (2008) indicated that the feed rate was found out to be dominant factor on the surface roughness, but it decreased with decreasing cutting speed, feed rate, and depth of cut in turning AISI 1050 hardened steels by CBN cutting tool. The RSM predicted and experimental surface roughness values were found to be very close. Singh and Rao (2007) developed mathematical model for surface roughness using RSM. Feed was the dominant factor determining the surface finish followed by nose radius and cutting velocity in finish hard turning of the bearing steel AISI 52100 using mixed ceramic inserts. Though, the effect of the effective rake angle on the surface finish was less, the interaction effects of nose radius and effective rake angle were considerably significant. In an experimental study of Lalwani et al. (2008), depth of cut was found to be the dominant contributor to the feed force in turning hardened MDN250 steel (50 HRC) using coated ceramic tool. In the thrust force and cutting force, feed rate and depth of cut contributed more. Horng et al. (2008) studied the machinability evaluation of austenitic Hadfield steel in the hard turning using $\mathrm{Al}_{2} \mathrm{O}_{3} / \mathrm{TiC}$ mixed ceramics tool $\left(70 \% \mathrm{Al}_{2} \mathrm{O}_{3}, 30 \% \mathrm{TiC}\right)$ for flank wear and surface roughness.

Cutting speed and interaction effect of feed rate with nose radius of tool was the main factors influencing the flank wear. For surface roughness, the most influencing factor was the cutting speed and the tool corner radius. Aggarwala et al. (2008) investigated the power consumption in hard turning of AISI P-20 tool steel (32-36 HRC) using TiN coated carbide insert with Taguchi's and RSM technique. Cryogenic environment was the most significant factor in minimizing power consumption followed by cutting speed and depth of cut. The effects of feed rate and nose radius were found to be insignificant. RSM technique was found to be better than Taguchi's method. Ozel and Karpat (2005) developed regression and ANN models in finish hard turning of AISI H13 steel for surface roughness and tool wear. Decrease in the feed rate, better was the surface roughness but slightly faster tool wear development. Increasing cutting speed resulted in significant increase in tool wear development but resulted in better surface roughness. Increase in the workpiece hardness resulted in better surface roughness with higher tool wear. More et al. (2006) investigated CBN-TiN composite-coated carbide inserts for hard turning of AISI 4340 steel ( 53 HRC). The flank wear was mainly due to abrasion in the machining of hardened AISI 4340 steel. The crater wear of the CBN-TiN coated inserts was found to be less than that of the PCBN inserts because of the lubricity of TiN layer. The coated inserts produced good surface finish and yielded a tool life of $18 \mathrm{~min}$. The machining cost reduction was found for $\mathrm{cBN}-$ TiN coated carbide tools compared to PCBN tools.

Sahoo and Sahoo (2011) developed mathematical model for flank wear and surface roughness in hard turning using coated carbide insert and correlated for its significance. It shows the high correlation between the experimental and predicted values. From ANOVA table, it is evident that, feed is the significant factor affecting surface roughness followed by cutting speed. For flank wear, cutting speed is the most significant factor followed by depth of cut. Feed is found to be insignificant for flank wear. Sahoo and Sahoo (2011) investigated the performance of coated carbide insert in machining D2 steel using response surface methodology and high correlation was established with this proposed methodology. Sahoo et al. (2011) optimized multi-responses in machining hardened steel using grey based Taguchi method. It is evident that experimental results have been greatly improved through this approach. Sahoo et al. (2013) developed the $\mathrm{Al} / \mathrm{SiCp}(10 \%$ weight) metal matrix composite through a conventional casting process and studied its machinability characteristics in turning using multilayer TiN coated carbide insert under dry environment based on Taguchi's $\mathrm{L}_{9}$ orthogonal array. Abrasion is found to be the dominant wear mechanism from the experimental study. Yong Huang et al. (2007) suggested that abrasion, adhesion and diffusion primarily govern the $\mathrm{CBN}$ tool wear in hard turning. 
Models have been proposed to predict the flank and crater-wear propagation and evaluate the relative importance of each wear mechanism. Performance of CBN tools while machining 100Cr6 has been studied in detail by Yallese et al. (2009). The authors recommend a cutting speed range of 90$220 \mathrm{~m} / \mathrm{min}$ in which the tool-work combination yields a good result in terms of wear, roughness and temperature at chip-tool interface. The authors also have detected significance of radial force and feed rate in this paper.

Tamizharasan et al. (2006) proposed that as an alternative to grinding, the hard turning produced better surface finish, lower flank wear rate and high material removal on the selected crank pin material by low content CBN tool. Thamizhmanii and Hasan (2008) concluded that the surface roughness was low by $\mathrm{CBN}$ at high cutting speed but the flank wear was high during machining stainless steel (45-55 $\mathrm{HRC}$ ). The surface roughness was high for PCBN tool than $\mathrm{CBN}$ tool and flank wear recorded was low for PCBN tool than $\mathrm{CBN}$ tool. The CBN tool was unable to withstand heat at cutting zone and hence more flank wear occurred than PCBN tool. More crater wear formed on PCBN tools where as CBN tool produced less crater wear. The formation of crater wear on the rake face was due to rough surface of saw tooth chips. Quiza et al. (2008) found that the neural network model performed better to make accurate predictions of tool wear than regression model in hard machining of D2 steel (60 HRC) using ceramic cutting tools.

Ozel et al. (2007) found that neural network model was suitable to predict tool wear and surface roughness patterns for a range of cutting conditions in finish hard turning of AISI D2 steels (60 HRC) using ceramic wiper (multi-radii) design inserts. Horng et al. (2008) developed RSM model using CCD in the hard turning using uncoated $\mathrm{Al}_{2} \mathrm{O}_{3} / \mathrm{TiC}$ mixed ceramics tool for flank wear and surface roughness. Flank wear was influenced principally by the cutting speed and the interaction effect of feed rate with nose radius of tool. The cutting speed and the tool corner radius affected surface roughness significantly. Basak et al. (2007) carried out the optimization of a finish hard turning process for the machining of D2 steel with ceramic tools using neural network models to predict the surface roughness and tool wear as functions of cutting speed, feed, and machining time and found suitable to choose the appropriate process parameters. Cemal Cakir et al. (2009) developed mathematical model $\left(1^{\text {st }}\right.$ order, $2^{\text {nd }}$ order and exponential) for surface roughness in hard turning of AISI P20 steel [52-54 HRC] using CVD coated carbide [TiCN $\left./ \mathrm{Al}_{2} \mathrm{O}_{3} / \mathrm{TiN}\right]$ and PVD TiAlN coated carbide inserts. Higher feed rates produced higher surface roughness values, whereas cutting speed had a contrary effect and cutting depth did not significantly effect. Second order model was the most appropriate one with its total average error being the smallest. Chien and Tsai (2003) developed a predictive model (backpropagation neural network) for the tool flank wear and GA optimization model in turning 17-4PH stainless steel (38-40 HRC) using TiN coated tool. The predictive model was capable of predicting the tool flank wear. Bhattacharya et al. (2009) employed Taguchi approach to study the effects of cutting parameters on finish and power consumption during high speed machining of AISI 1045 steel (50 HRC) by coated carbide tool (TiC/TiN).

Cutting speed was the significant parameter on surface roughness and power consumption, while feed and depth of cut did not substantially affect the responses. Paiva et al. (2007) studied alternative hybrid approach combining response surface methodology (RSM) and principal component analysis (PCA) to optimize multiple correlated responses in turning of AISI 52100 steel with mixed ceramic tool. The approach was adequate where the multiple responses exhibited some correlation. A second-order model proved more appropriate. Sahoo and sahoo (2012) some machinability studies on flank wear, surface roughness, chip morphology and cutting forces in finish hard turning of AISI 4340 steel using uncoated and multilayer TiN and $\mathrm{ZrCN}$ coated carbide inserts at higher cutting speed range. The process has also been justified economically for its effective application in hard turning. Al-Ahmari (2007) developed machinability models for tool life, cutting force and surface roughness using response surface methodology and ANN in machining austenitic AISI 302 steel. ANN model was found to be better than regression model and RSM model. In addition, RSM models were found to be superior to regression 
model for predicting tool life and cutting force. Thangavel and Selladurai (2008) applied fractional factorial approach on the surface roughness during turning EN24 steel by uncoated carbide insert and developed mathematical model using RSM. The depth of cut did not affect the surface roughness. The tool nose radius and feed rate affected the surface roughness significantly. The most significant interactions were found between feed and nose radius. Singh and Kumar (2007) developed mathematical models of tool life and surface roughness for turning EN24 steel with TiC coated carbide. RSM model was found suitable. Sahoo and Sahoo (2013) studied the turning of hardened AISI 4340 steel $(47 \pm 1 \mathrm{HRC})$ using coated carbide inserts $\left(\mathrm{TiN} / \mathrm{TiCN} / \mathrm{Al}_{2} \mathrm{O}_{3} / \mathrm{ZrCN}\right)$ under dry environment. Abrasion is found to be the dominant wear mechanisms in hard turning. The mathematical model shows high determination coefficient and fits the actual data well.

Thus, the objective of the present work has been set to have a machinability study to evaluate the performance of PVD TiN coated mixed ceramic inserts under varying parameter of machining hardened EN24 steel (50 HRC) under dry environment in context of evolution of flank wear. The mathematical model has been developed for prediction of flank wear using response surface methodology and correlated for its significance. The response contour plots have been analyzed to find out the best optimal combination of cutting parameters for minimum flank wear in machining.

\section{Experimental details}

\subsection{Workpiece}

To comply with the objectives of the research, the workpieces was taken in the form of round bars of diameter $45 \mathrm{~mm}, 200 \mathrm{~mm}$ length EN 24 medium carbon low alloy high strength steel (50 HRC). The heat treated samples were cleaned by removing the hardened outer skin by machining to get the required diameter. The end faces were turned. Typical applications are for highly stressed components of large cross section for structural use such as aircraft landing gear, power transmission gears and shafts, automotive and general engineering application such as propeller shafts, connecting rods, gear shafts and crankshafts, landing gear components, heavy roughing such as rotary shafts and discs etc.

\subsection{Machine tool}

The machine tool used was a high rigid CNC lathe (AMS, India) having maximum spindle speed of $3500 \mathrm{rpm}$ and power of $16 \mathrm{KW}$ with Sinumeric controller.

\subsection{Cutting inserts}

In tests, PVD TiN coated mixed ceramic insert $\left(\mathrm{Al}_{2} \mathrm{O}_{3}+\mathrm{TiCN}\right)$ of ISO designation CNGA 120408 SO3030, grade A66N ( $80^{\circ}$ diamond shaped insert) mounted on a PCLNR2525 M12 tool holder has been employed for experimentation (Fig.1). The insert with tool holder has the nose radius of $0.8 \mathrm{~mm}$ and major cutting edge angle or approach angle of $95^{\circ}$ with back rake angle of $-6^{0}$.

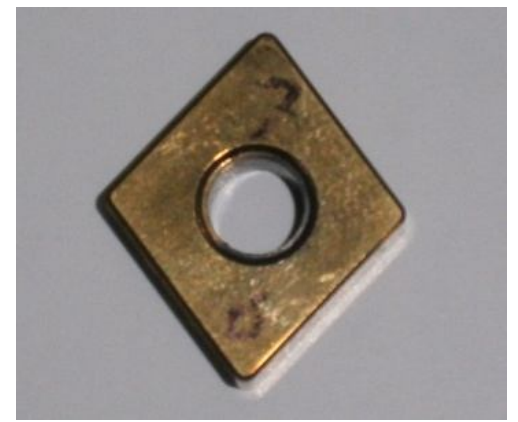

Fig.1. Image of cutting insert 


\subsection{Experimental design}

Experimental design is an important engineering tool for improving the process and provides information concerning which factors is most influential one. In the study, a full factorial design $\left(3^{3}\right)$ of experiment (DOE) has been used to be effectively investigated. The independent variables in the study were the cutting speed, feed and machining time with three levels each. The dependent variable is flank wear of inserts. This comprises of total 27 runs. The cutting parameters and their levels are shown in Table 1. The experiments are carried out under dry environment. Throughout the experiment, depth of cut is fixed as $0.2 \mathrm{~mm}$.

\section{Table1}

Machining parameters levels

\begin{tabular}{lcccc}
\hline Machining parameter & Symbol & Level 1 & Level 2 & Level 3 \\
\hline Cutting speed & $\mathrm{v}$ & 70 & 110 & 150 \\
Feed, mm/rev & $\mathrm{f}$ & 0.05 & 0.1 & 0.15 \\
Machining time, min & $\mathrm{t}$ & 5 & 12 & 20 \\
\hline
\end{tabular}

\subsection{Measurement}

Flank wear has been measured by using Nikon profile projector (V10 AD) and scanning electron microscope (JEOL, JSM, 6390LV, Japan). The criteria of flank wear is taken as VBc $=0.3 \mathrm{~mm}$ and measured at tool nose corner. As the depth of cut $(0.2 \mathrm{~mm})$ is less than the nose radius $(0.8 \mathrm{~mm})$, the tool wear occurred in the vicinity of nose corner only.

\section{Experimental results and discussions}

The experimental results are shown in Table 2. It has been observed that the flank wear evolution was steady without any premature failure and remains within recommended limit of $0.3 \mathrm{~mm}$ when cutting is performed with ceramic inserts under entire range of cutting speed-feed-machining time combinations. The flank wear value increases with increasing cutting speed, feed and machining time. No chipping or catastrophic failure is observed during machining of hardened EN 24 steel with PVD TiN coated mixed ceramic inserts under dry environment. However, at extreme parametric conditions, the flank wear value is observed to be higher compared to other parametric ranges. Abrasion and diffusion has been found to be dominant wear mechanism from SEM micrograph (Fig. 2). The abrasion wear may be attributed due to the friction phenomenon at the interfaces combined with high pressure which are the result of the interaction between machined material hardened phases and the components of tool. By increasing cutting speed, interface temperature rises quickly and softens the tool material resulting diffusion mechanism (favours chemical reaction) to be active. The combination of these two mechanisms accelerates wearing process. The tool tip is not able to bear the abrasive action of the chip; the heat generated and consequently fails at faster rate. The tool tip SEM micrographs in Fig. 2 clearly depict the condition of the tool for extreme parametric conditions $(\mathrm{v}=150 \mathrm{~m} / \mathrm{min}, \mathrm{f}=0.15 \mathrm{~mm} / \mathrm{rev}$ and $\mathrm{t}=20 \mathrm{~min})$.

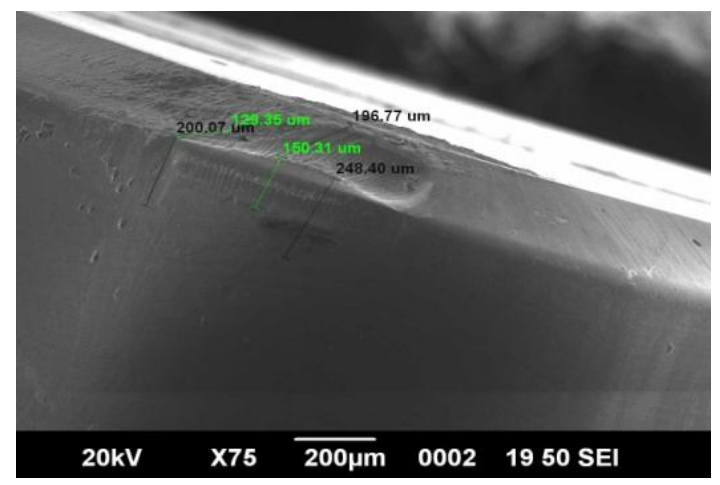

Fig.2. SEM micrograph at $v=150 \mathrm{~m} / \mathrm{min}, \mathrm{f}=0.15 \mathrm{~mm} / \mathrm{rev}$ and $\mathrm{t}=20 \mathrm{~min}$ 
Table 2

Experimental results of flank wear (VBc)

\begin{tabular}{|c|c|c|c|c|}
\hline Expt. No & $\mathrm{V}$ & $\mathrm{f}$ & $\mathrm{t}$ & $\mathrm{VBc}(\mathrm{mm})$ \\
\hline 1 & 1 & 1 & 1 & 0.021 \\
\hline 2 & 1 & 1 & 2 & 0.073 \\
\hline 3 & 1 & 1 & 3 & 0.133 \\
\hline 4 & 1 & 2 & 1 & 0.04 \\
\hline 5 & 1 & 2 & 2 & 0.114 \\
\hline 6 & 1 & 2 & 3 & 0.153 \\
\hline 7 & 1 & 3 & 1 & 0.059 \\
\hline 8 & 1 & 3 & 2 & 0.112 \\
\hline 9 & 1 & 3 & 3 & 0.152 \\
\hline 10 & 2 & 1 & 1 & 0.046 \\
\hline 11 & 2 & 1 & 2 & 0.103 \\
\hline 12 & 2 & 1 & 3 & 0.159 \\
\hline 13 & 2 & 2 & 1 & 0.066 \\
\hline 14 & 2 & 2 & 2 & 0.118 \\
\hline 15 & 2 & 2 & 3 & 0.179 \\
\hline 16 & 2 & 3 & 1 & 0.081 \\
\hline 17 & 2 & 3 & 2 & 0.138 \\
\hline 18 & 2 & 3 & 3 & 0.198 \\
\hline 19 & 3 & 1 & 1 & 0.072 \\
\hline 20 & 3 & 1 & 2 & 0.125 \\
\hline 21 & 3 & 1 & 3 & 0.182 \\
\hline 22 & 3 & 2 & 1 & 0.07 \\
\hline 23 & 3 & 2 & 2 & 0.144 \\
\hline 24 & 3 & 2 & 3 & 0.204 \\
\hline 25 & 3 & 3 & 1 & 0.085 \\
\hline 26 & 3 & 3 & 2 & 0.19 \\
\hline 27 & 3 & 3 & 3 & 0.248 \\
\hline
\end{tabular}

\section{Response surface model}

Response surface methodology (RSM) is a collection of mathematical and statistical techniques (Montgomery, 1997) that are useful for the modeling and analysis of problems in which output or response is influenced by several input variables and the objective is to find the correlation between the response and the variables investigated. To test the fit of the model, the regression equation and determination coefficient $\left(\mathrm{R}^{2}\right)$ were calculated (Singh \& Rao, 2007) and acceptance was based on high to very high coefficients of correlation $\left(\mathrm{R}^{2}\right)$. The second order response surface representing the flank wear (VBc) can be expressed as a function of cutting parameters such as $\mathrm{v}, \mathrm{f}$ and $\mathrm{t}$. The relationship between the surface roughness and machining parameters has been expressed as follows:

$$
\begin{aligned}
\mathrm{VBc}= & -0.38762+0.000132 \mathrm{v}+0.063475 \mathrm{f}+0.008296 \mathrm{t}+0.0000 \mathrm{v}^{2}+0.022222 \mathrm{f}^{2}-0.000156 \mathrm{t}^{2}+ \\
& 0.002 \mathrm{vf}+0.000025 \mathrm{vt}+0.008097 \mathrm{ft} \\
& \mathrm{R}^{2}=98 \%, \mathrm{R}^{2}(\operatorname{adj})=96.8 \%
\end{aligned}
$$

Analysis of variance has been performed to judge the significance of regression terms for adequacy of model. Result of ANOVA for the response function flank wear model is shown in Table 3. This analysis is carried out for a level of confidence of $95 \%$. Models are developed using uncoded units. If the p-value in ANOVA table is less than 0.05 then the model, the factors, interaction of factors and curvature are said to be significant. However, the calculated coefficients of the model equation need to be tested for statistical significance. Regression, linear and interaction terms are statistically significant because $\mathrm{P}$ value is less than 0.05 . In addition, the calculated value of $\mathrm{F}$ is greater than $\mathrm{F}$ table value (2.49) showing significance of regression terms and model. The coefficient of determination is particularly calculated in the analysis of response surface model and higher $\mathrm{R}^{2}$ (approaches to unity) shows the most significance of model developed. 
The RSM model presented high determination coefficient $\left(\mathrm{R}^{2}=0.98\right.$ close to unity) explaining $98 \%$ of the variability in the response which indicates the goodness of fit for the model and high significance of the model. In our model the adjusted $\mathrm{R}^{2}$ value is very close to the predicted $\mathrm{R}^{2}$. So the predicted $\mathrm{R}^{2}$ is in reasonable agreement with the adjusted $\mathrm{R}^{2}$. It is understood that unnecessary terms are not added in the model. This analysis showed that the prediction model sufficiently explains the relationship between flank wear and the independent variables. Thus the RSM model developed can be effectively used to predict the flank wear during machining hardened EN 24 steel with ceramic insert.

Table 3

ANOVA for flank wear model.

\begin{tabular}{lcccccc}
\hline Source & DF & Seq SS & Adj SS & Adj MS & F & P \\
\hline Regression & 9 & 0.0831 & 0.0831 & 0.0092 & 88.1 & 0.000 \\
Linear & 3 & 0.0817 & 0.0013 & 0.0004 & 4.23 & 0.021 \\
Square & 3 & 0.0004 & 0.0004 & 0.0001 & 1.45 & 0.263 \\
Interaction & 3 & 0.0009 & 0.0009 & 0.0003 & 3.04 & 0.05 \\
Residual error & 17 & 0.0017 & 0.0017 & 0.0001 & & \\
\hline Total & 26 & 0.0849 & & &
\end{tabular}

From main effect plot (Fig. 3), it is evident that, machining time is the significant factor affecting flank wear followed by cutting speed and feed.

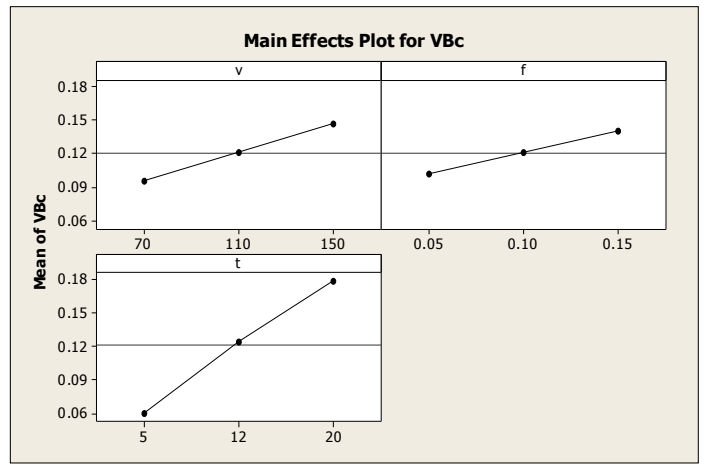

Fig. 3. Main effect plot of flank wear (VBc)

Analysis of variance has also been conducted to judge the significance of process parameter on responses at $95 \%$ confidence level. From ANOVA Table 4, it is revealed that machining time has the greater influence on flank wear as P-value is less than 0.05 and $\mathrm{F}$ calculated value is more than $\mathrm{F}$ table value. Cutting speed is the second dominant parameter on flank wear followed by feed. From interaction effect plot (Fig. 4), it shows that, cutting speed-machining time and feed-machining time are significant. In addition to this, the adequacy of the model is also investigated by the examination of residuals. The residuals are the differences between the observed and the predicted responses and these are examined using the normal probability plots of the residuals. If the model is adequate, the points on the normal probability plots of the residuals should form a straight line. On the other hand, the plots of the residuals versus the predicted response should be structure less, that is, they should contain no obvious patterns.

\section{Table 4}

ANOVA for flank wear

\begin{tabular}{lcccccc}
\hline Source & DF & SS & MS & F & P & Remarks \\
\hline v & 2 & 0.0119 & 0.0059 & 43.48 & 0.000 & Significant \\
f & 2 & 0.0067 & 0.0033 & 24.71 & 0.000 & Significant \\
t & 2 & 0.0635 & 0.0317 & 231.88 & 0.000 & Significant \\
Error & 8 & 0.0009 & 0.0001 & & & \\
\hline Total & 26 & 0.0849 & & & & \\
\hline
\end{tabular}


A check on the normal probability plot vs. residuals of RSM model (Fig. 5) shows that the residuals lie reasonably close to a straight line implying that errors are distributed normally and giving support that the terms mentioned in the model are significant. The normal probability plot does not show any outliers at extremes but its standardized residual value was 2.07 i.e. less than 3 which should cause no concern. Also in visualizing the straight line of normal probability plot, more emphasis should be given on the central values than on the extremes.

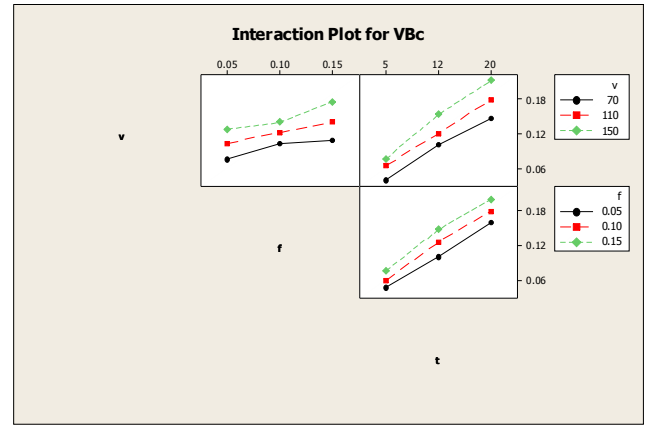

Fig.4. Interaction plot of flank wear (VBc)

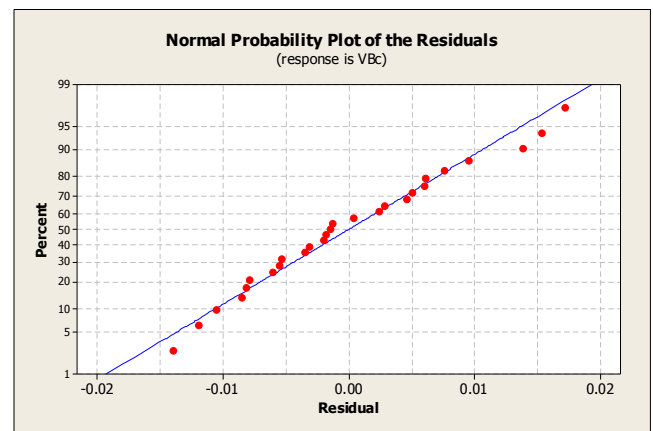

Fig. 5. Normal probability plot of the residuals

Also the predicted and experimental values are very close to each other showing significance of model developed (Fig. 6). The residuals between the experiment and predicted value are very less and closely fitted. The response contour plots have been shown in cutting speed-feed plane and cutting speedmachining time plane respectively from which the best optimal combination of cutting parameters for minimum flank wear can be predicted. These response contours can help in the prediction of the flank wear at any zone of the experimental domain. From the contour plots in Fig. 7 and 8, the optimal parametric combination for lowest flank wear has been found to be v1-f1-t1 (i.e. cutting speed at 70 $\mathrm{m} / \mathrm{min}$, feed at $0.05 \mathrm{~mm} / \mathrm{rev}$ and machining time of 5 minute). Both have curvilinear profile in accordance to the quadratic model fitted. Contour plots developed from analysis of results can be used for selecting the process parameters for desired flank wear values.

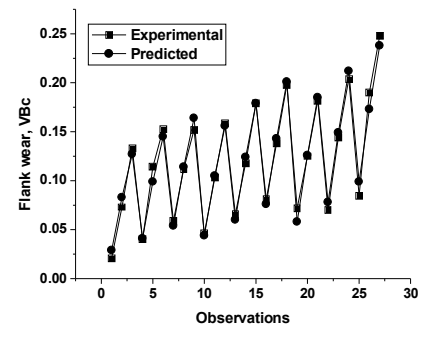

Fig.6. Experimental vs. predicted values of flank wear

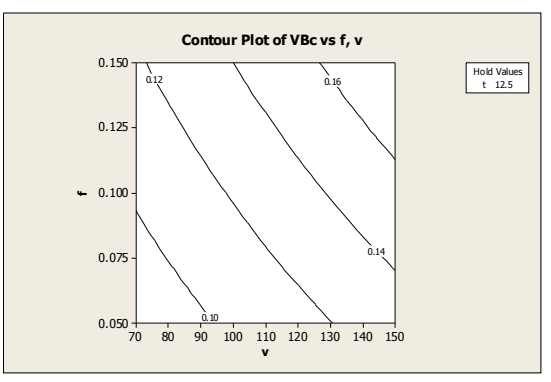

Fig.7. Contour plot of flank wear $(\mathrm{VBc})$ in $\mathrm{v}-\mathrm{f}$ plane

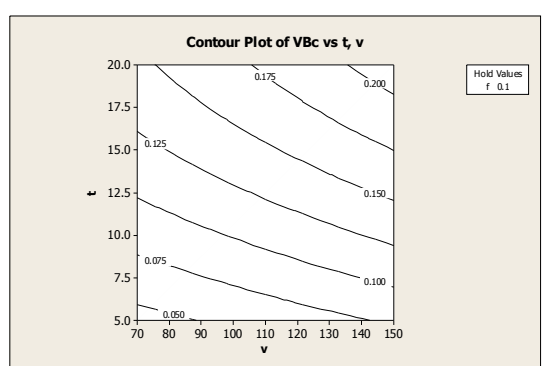

Fig.8. Contour plot of flank wear $(\mathrm{VBc})$ in $\mathrm{v}$-t plane

\section{Conclusions}

Based on the above discussions, following conclusions can be drawn.

1. Abrasion and diffusion are found to be dominant wear mechanism in hard machining of EN 24 steel using PVD TiN coated mixed ceramic insert under dry environment.

2. Machining time has the most significance parameter of flank wear followed by cutting speed and feed. Besides, interaction of machining time-cutting speed and machining time-feed are also significant. 
3. Flank wear response surface model proposed is significant because of high determination coefficients $\left(\mathrm{R}^{2}=0.98\right.$ close to unity). The residuals lie reasonably close to a straight line implying that the terms mentioned in the model are significant observed from normal probability plot.

4. The predicted flank wear value from RSM model and experimental values are very close to each other showing significance of model developed

5. From the contour plots, the optimal parametric combination for lowest flank wear is v1-f1-t1. Both have curvilinear profile in accordance to the quadratic model fitted.

6. This indicates that the developed model can be effectively used to predict the flank wear in the hard turning using mixed ceramic inserts.

\section{Acknowledgements}

The authors greatly appreciate and acknowledge the support and cooperation's rendered by CTTC, Bhubaneswar and School of Mechanical Engineering, KIIT University to carry out this research work.

\section{References}

Aggarwala, A., Singh, K., Kumar, P., \& Singh, M. (2008). Optimizing power consumption for CNC turned parts using response surface methodology and Taguchi's technique-A comparative analysis. Journal of Materials Processing Technology, 200, 373-384.

Al-Ahmari, A.M.A. (2007). Predictive machinability models for a selected hard material in turning operations. Journal of Materials Processing Technology, 190, 305-311.

Basak, S., Dixit, U.S., \& Davim, J.P. (2007). Application of radial basis function neural networks in optimization of hard turning of AISI D2 cold-worked tool steel with a ceramic tool. Proc. IMechE, Part B: Journal of Engineering Manufacture, 221, 987-998.

Bhattacharya, A., Das, S., Majumder, P., \& Batish, A. (2009). Estimating the effect of cutting parameters on surface finish and power consumption during high speed machining of AISI 1045 steel using Taguchi design and ANOVA. Production Engineering, 3(1), 31-40.

Cemal Cakir, M., Ensarioglu, C., \& Demirayak, I. (2009). Mathematical modeling of surface roughness for evaluating the effects of cutting parameters and coating material. Journal of Materials Processing Technology, 209 (1), 102-109.

Chien, W-T., \& Tsai, C-S. (2003). The investigation on the prediction of tool wear and the determination of optimum cutting conditions in machining 17-4PH stainless steel. Journal of Materials Processing Technology, 140, 340-345.

Horng, J-T., Liu, N-M., \& Chiang, K. (2008). Investigating the machinability evaluation of Hadfield steel in the hard turning with $\mathrm{Al}_{2} \mathrm{O}_{3} / \mathrm{TiC}$ mixed ceramic tool based on the response surface methodology. Journal of Materials Processing Technology, 208 (1-3), 532-541.

Horng, J-T., Liu, N-M., \& Chiang, K-T. (2008). Investigating the machinability evaluation of Hadfield steel in the hard turning with $\mathrm{Al}_{2} \mathrm{O}_{3} / \mathrm{TiC}$ mixed ceramic tool based on the response surface methodology. Journal of Materials Processing Technology, 208 (1-3), 532-541.

Huang, Y., Kevin Chou, Y., \& Liang, S.Y. (2007). CBN tool wear in hard turning: a survey on research progresses. International Journal of Advanced Manufacturing Technology, 35, 443-453.

Lalwani, D.I., Mehta, N.K., \& Jain, P.K. (2008). Experimental investigations of cutting parameters influence on cutting forces and surface roughness in finish hard turning of MDN250 steel. Journal of Materials Processing Technology, 206 (1-3), 167-179.

Montgomery, D.C. (1997). Design and Analysis of Experiments, $4^{\text {th }}$ ed. Wiley, New York.

More, A.S., Jiang, W., Brown, W.D., \& Malshe, A.P. (2006). Tool wear and machining performance of cBN-TiN coated carbide inserts and PCBN compact inserts in turning AISI 4340 hardened steel. Journal of Materials Processing Technology, 180, 253-262. 
O” zel, T., Karpat, Y., Figueira, L., \& Davim, J.P. (2007). Modelling of surface finish and tool flank wear in turning of AISI D2 steel with ceramic wiper inserts. Journal of Materials Processing Technology, 189, 192-198.

Ozel, T., \& Karpat, Y. (2005). Predictive modeling of surface roughness and tool wear in hard turning using regression and neural networks. International Journal of Machine Tools \& Manufacture, 45, 467-479.

Paiva, A.P., Ferreira, J.R., \& Balestrassi, P.P. (2007). A multivariate hybrid approach applied to AISI 52100 hardened steel turning optimization. Journal of Materials Processing Technology, 189, 2635.

Quiza, R., Figueira, L., \& Davim, J.P. (2008). Comparing statistical models and artificial neural networks on predicting the tool wear in hard machining D2 AISI steel. International Journal of Advanced Manufacturing Technology, 37, 641-648.

Sahoo, A.K., \& Sahoo, B. (2012). Experimental investigations on machinability aspects in finish hard turning of AISI 4340 steel using uncoated and multilayer coated carbide inserts. Measurement, 45, 2153-2165.

Sahoo, A.K., \& Sahoo, B. (2011). Mathematical modelling and multi-response optimisation using response surface methodology and grey based Taguchi method: an experimental investigation. Int. J. Experimental Design and Process Optimisation, 2(3), 221-242.

Sahoo, A.K. \& Sahoo, B. (2011). Surface roughness model and parametric optimization in finish turning using coated carbide insert: Response surface methodology and Taguchi approach. International Journal of Industrial Engineering Computations, 2, 819-830.

Sahoo, A.K., \& Orra, K., Rout, A.K., \& Routra, B.C. (2011). Multi-response optimization in machining hardened steel using Grey-based Taguchi method. International Journal of Manufacturing Technology and Industrial Engineering, 1(1), 7-12.

Sahoo, A.K., Pradhan, S., \& Rout, A.K. (2013). Development and machinability assessment in turning $\mathrm{Al} / \mathrm{SiCp}$-metal matrix composite with multilayer coated carbide insert using Taguchi and statistical techniques. Archives of civil and mechanical engineering, 13, 27-35.

Sahoo, A.K., \& Sahoo, B. (2013). Experimental investigation on flank wear and tool life, cost analysis and mathematical model in turning hardened steel using coated carbide inserts. International Journal of Industrial Engineering Computations, doi: 10.5267/j.ijiec.2013.05.003.

Sahin, Y., \& Motorcu, A.R. (2008). Surface roughness model in machining hardened steel with cubic boron nitride cutting tool. International Journal of Refractory Metals \& Hard Materials, 26, 84-90.

Singh, D., \& Rao, P.V. (2007). A surface roughness prediction model for hard turning process, International Journal of Advanced Manufacturing Technology, 32, 1115-1124.

Singh, H., \& Kumar, P. (2007). Mathematical models of tool life \& surface roughness for turning operation through response surface methodology. Journal of Scientific \& Industrial research, 66, 220-226.

Singh, D., \& Rao, P.V. (2007). A surface roughness prediction model for hard turning process. International Journal of Advanced Manufacturing Technology, 32 (11-12), 1115-1124.

Tamizharasan, T., Selvaraj, T., \& Noorul Haq, A. (2006). Analysis of tool wear and surface finish in hard turning. International Journal of Advanced Manufacturing Technology, 28, 671-679.

Thamizhmanii, S., \& Hasan, S. (2008). Measurement of surface roughness and flank wear on hard martensitic stainless steel by CBN and PCBN cutting tools. Journal of Achievements in Materials and Manufacturing Engineering, 31 (2), 415-421.

Thangavel, P., \& Selladurai, V. (2008). An experimental investigation on the effect of turning parameters on surface roughness. International Journal of Manufacturing Research, 3 (3), 285-300.

Tönshoff, H., Wobker, H., \& Brandt, D. (1995). Hard turning - influences on the workpiece properties. Transactions of NAMRI/SME, 23, 215-220.

Yallese, M.A., Chaoui, K., Zeghib, N., Boulanouar, L., \& Rigal, J-F. (2009). Hard machining of hardened bearing steel using cubic boron nitride tool. Journal of Materials Processing Technology, 209, 1092-1104. 